\title{
EL SANTO ÁNGEL CUSTODIO \\ DE LA IGLESIA DE SAN FRANCISCO: UNA NUEVA OBRA DE JUAN DE ASTORGA EN TARIFA (CÁDIZ)
}

\author{
THE HOLY CUSTODIAN ANGEL AT THE CHURCH \\ OF SAINT FRANCIS OF ASSISI: A NEW WORK BY \\ THE SCULPTOR JUAN DE ASTORGA IN TARIFA (CÁDIZ)
}

\author{
Rafael Cazalla Urbano \\ Instituto de Estudios Campogibraltareños. España \\ ORCID: 0000-0003-0524-914X \\ rafaelcazallaurbano@hotmail.com
}

\begin{abstract}
En el presente trabajo realizamos un análisis estilístico e iconográfico de la imagen del Santo Ángel Custodio que se venera en la iglesia parroquial de San Francisco de Asís de la localidad de Tarifa (Cádiz) y que consideramos obra personal del escultor archidonense Juan de Astorga (1779-1849).

Palabras clave: escultura; neoclasicismo; Juan de Astorga; Santo Ángel Custodio; Tarifa.

In the present paper we perform a stylistic and iconographic analysis of the image of the Holy Custodian Angel, which is located at the Church of Saint Francis of Assisi in the town of Tarifa (Cádiz) and we attribute as a personal work to the Archidonian sculptor Juan de Astorga (1779-1849).

Keywords: sculpture; Neoclassicism; Juan de Astorga; Holy Custodian Angel; Tarifa.
\end{abstract}

\section{LA IMAGEN DEL ÁNGEL CUSTODIO DE LA IGLESIA DE SAN FRANCISCO DE ASÍS}

En un manuscrito que describe los altares existentes en los templos tarifeños en abril de 1819, no hay referencia a ninguna imagen del Santo Ángel Custodio en la iglesia parroquial de San Francisco, siendo la primera fuente que constata su existencia el informe elaborado por el párroco de dicha iglesia en 1880, 
describiéndose su altar en estos términos: "Del Ángel Custodio: [...] Su simulado retablo presenta en el fondo un camarín embellecido por una magnifica escultura del Santo Ángel con otra del niño Tobías conducido por Aquél"'. Además, por el inventario de alhajas del mismo informe, sabemos que el ángel portaba una diadema de plata, hoy desaparecida. Similar descripción encontramos años más tarde, en 1919, en un nuevo informe sobre el templo elaborado por el párroco: "el altar del santo Ángel Custodio constaba de un marco de madera dorada. En el centro la imagen del titular en madera $[\ldots] " 2$. Pocos más datos o referencias se encuentran sobre esta imagen, cuyo origen se desconoce y cuya llegada al templo tarifeño ha de relacionarse con la reedificación de la iglesia parroquial de San Francisco en 1797 y la dotación de nuevos altares desde entonces y a lo largo de los primeros años del siglo XIX.

Esa misma imagen del Ángel Custodio se encuentra actualmente en una simple hornacina abierta en el testero izquierdo de la capilla del Sagrario, ubicación que tampoco es la original de su antiguo retablo. En efecto, según comprobamos en una postal fotográfica fechada en la década de 1940, la imagen del Santo Ángel y su retablo se encontraban originalmente en el segundo tramo de la nave del evangelio (Figura 1), donde posiblemente estuvo hasta comienzos de la década de 1960, cuando, después de una visita pastoral en 1961, el entonces obispo auxiliar de Cádiz, Antonio Añoveros, haciendo una interpretación muy particular o en exceso de los dictados del Concilio Vaticano II, ordenó que se desmontaran algunos altares del templo y se retiraran varias de las imágenes expuestas.

El conjunto escultórico está formado por las imágenes del Ángel Custodio y la de un niño a su izquierda, al que acompaña. Ambas de madera policromada. El ángel mide $110 \mathrm{~cm}$ de alto y el niño 60, ambas desde el suelo, midiendo la peana $5 \mathrm{~cm}$. Muchos han querido identificar, erróneamente, al niño con Tobías, como es el caso del informe elaborado en 1880 . No obstante, como hemos dicho, la iconografía está tomada precisamente del libro de Tobías, pero en este caso no podríamos identificarlo como tal, puesto que San Rafael acompañaría en su viaje a un Tobías más mayor, pues estaría en edad casadera y no tan infantil, amén de que se representa una advocación diferente y, por tanto, los atributos difieren también. Se trataría por tanto, de la clásica iconografía del Ángel de la Guarda que protege al alma cristiana representada en el niño, guiándola en el camino de la vida, un asunto tomado del pasaje del libro del Éxodo 3 .

Las dos imágenes muestran un contraposto, dejando caer sus cuerpos sobre sus respectivas piernas derechas, quedando flexionadas levemente las izquierdas (Figura 2). El ángel toca suavemente con su mano izquierda la cabeza del niño,

1 Terán Gil, 2002: 23.

2 Criado Atalaya, 2003: 445-456.

${ }^{3}$ Ex 23, 20-22: "Mira, yo enviaré mi ángel delante de ti para que te cuide en el camino y te lleve al lugar que te he preparado". 
mostrando su protección, mientras que la derecha, a pesar de que la mayoría de las veces que vemos esta iconografía señala al cielo, en esta ocasión se la lleva al pecho, revelando su intercesión a la persona a la que custodia. De hecho, sus dedos señalan su corazón, recalcando que él es su protector. El niño parece responder y obedecer a esa oración, pues igualmente se lleva su mano derecha al pecho, mientras que la izquierda la eleva levemente, en un ademán de tener una conversación con su guardián, que parece escucharlo con atención y dulzura.

El Custodio viste una túnica roja de cuello redondo dorado, remangada hasta debajo de los codos, dejando descubiertos sus antebrazos. Le llega hasta los pies con aberturas hasta algo más arriba de las rodillas. Es roja con un esgrafiado en zig-zag que intenta imitar las características aguas de los tejidos de muaré, acompañada de decoración con motivos vegetales dorados en las aberturas de las piernas simulando bordados. Porta un manto verde que le cubre su hombro izquierdo cayendo por su espalda, con rayas horizontales doradas y con una cenefa de espigas doradas en los bordes del mismo, anudándose en la parte delantera a una cinta de color blanco y con decoración dorada a base de líneas diagonales que alterna una ancha por cada dos estrechas, ciñendo su cintura. Sus alas son grandes, doradas en su parte superior, y con plumas en relieve rojas en su parte intermedia y verdes en los extremos inferiores, también trabajadas con rayas doradas en su parte frontal, ya que la trasera está tan solo pintada con los mismos colores que la delantera, pero con largas y abocetadas pinceladas, careciendo de la primera capa de pan de oro. Hemos de suponer que, siendo las alas la parte final del trabajo y al ser una imagen que sería destinada, en principio, para un retablo, no llegara el presupuesto a cubrir la totalidad de la obra, quedando estas sin esa terminación detallada, pues tanto la túnica como el manto tienen la policromía perfectamente rematadas.

El niño viste una túnica verde, con figuras romboidales doradas a modo de malla, igualmente remangada hasta debajo de sus codos permitiéndonos ver sus antebrazos, y una cinta dorada en su totalidad que se anuda con un lazo en el centro. Esta le llega por debajo de la rodilla; sin embargo, el contraposto nos permite ver su rodilla izquierda. Es decir, el estofado de ambas imágenes deja patente el estilo neoclásico con esa simulación fiel de los tejidos lisos y paños naturales, de ahí que el esgrafiado sobre el temple sea de distinto grosor, a lo que sumamos, sobre todo en los bordes del manto del ángel y en las aberturas de las piernas, unos bordados a modo de pasamanería y formas vegetales que van en sintonía con los encajes del momento.

Si el niño va descalzo, el ángel calza unas sandalias cuyo remate en el empeine, casi a la altura del tobillo y a modo de lengüeta, es de tela. Los rostros de ambos son ovalados, algo más redondo y de mejillas rellenitas en el niño, incluso posee una pequeña papada (Figura 3). Tienen unas cejas finamente dibujadas, narices rectas, con un pequeño hoyuelo en la barbilla. El ángel tiene la boca ligeramente entreabierta, mientras que el niño la mantiene cerrada, dotándola, quizás, de una 
expresión ensimismada, atento a lo que su guía le va marcando o manteniendo un diálogo interior con él. Los ojos de ambos son de cristal; los del niño miran hacia arriba pero no directamente a la cara del ángel, de forma que ambas miradas están algo perdidas. La cabeza del ángel se encuentra ligeramente inclinada hacia su izquierda, con mirada baja e igual que la del niño, ensimismada e incluso dulce (Figura 4). Esa mirada, que nos transmite serenidad, se acentúa con una caída de párpados, quedando estos a mitad de los ojos. Esto queda subrayado por la policromía nacarada y rosácea de la encarnadura, al igual que la elegancia de los cuellos. Los cabellos están tratados de la misma manera en los dos, con golpes de gubia poco profundos, con peinado hacia abajo y con un pequeño mechón en el centro de sus cabezas a modo de copete. La diadema que poseía el ángel en su día ha desaparecido, portando hoy una aureola de latón dorada.

Llegados a este punto, a falta de más documentación hasta la fecha, y comparando la obra con algunas de autores que pudieran ser coetáneos como Cristóbal Ramos, Blas Molner, Cosme Velázquez, José Fernández Guerrero o Manuel González el Granadino, más adentrado en el siglo XIX y del que existen obras en el mismo templo, comprobamos que las características de esta imagen nos acercan al quehacer de Juan de Astorga. De hecho, nuestra imagen sigue un esquema compositivo muy similar a los suyos, siendo los rostros en su inmensa mayoría ovalados, con nariz recta, mirada algo perdida, con una leve caída de ojos, mejillas rellenitas y hoyuelo en la barbilla. Los semblantes son dulces, serenos, bellos, ensimismados, y nos llevan a la reflexión y meditación. Ejemplos de ellos los tenemos en las imágenes de la hermandad del Santo Entierro de Sevilla, concretamente en el misterio del Duelo, donde destacamos a María Magdalena y San Juan, ambas de 1829. No en vano, encontramos semejanzas con San Juan en la forma de tallar el cabello, recogiéndolo en los laterales, dejando descubierta media oreja a ambos lados, cayendo la melena por el cuello, incluso el mechón central a modo de copete, que termina en un rizo que dibuja una " $S$ " en sus frentes. Igual tratamiento encontramos en el San José de la iglesia de San Pedro, en Sevi1la. Por otro lado, tenemos la Virgen de la Esperanza de la hermandad de la Trinidad de Sevilla, de 1819; Nuestra Señora del Mayor Dolor de Ceuta, de 1828; y Nuestra Señora de la Presentación de la hermandad del Calvario de Sevilla, atribuida a Juan de Astorga y supuestamente realizada entre 1834 y $1839^{4}$. En todas ellas vemos esas mismas características en sus rostros, al igual que en el Ángel Custodio del templo tarifeño de San Francisco.

Pero Juan de Astorga también realizará imágenes como el San Juanito del convento de Santa Paula, en 1810-1811, o la del Buen Pastor, de la capilla Sacramental de la iglesia de Nuestra Señora de la Antigua de Almensilla, atribuido este último al maestro archidonense por Ruiz Alcañiz ${ }^{5}$. Ambas obras nos son de vital

\footnotetext{
${ }^{4}$ https://hermandaddelcalvario.org/ntra-sra-de-la-presentacion-2/ (06/03/2020)
}

5 Ruiz Alcañiz, 1986: 42. Roda Peña, 1991: 345. 
importancia ya que podemos compararlas con el niño del Ángel Custodio de Tarifa, encontrando multitud de semejanzas. También del mismo Juan de Astorga existe una imagen del Ángel Custodio en la localidad sevillana de Umbrete, documentada en el año $1827^{6}$. Esta hechura hay que ponerla en relación con la presencia del cardenal Francisco Javier Cienfuegos, quien presidió la diócesis hispalense desde 1824 hasta 1836, y quien fue un gran propagandista de la devoción al Custodio, promovida por el rey Fernando VII a partir de 1823 cuando recuperó el poder en España.

Este dato resulta especialmente clarificador, pues Cienfuegos había sido anteriormente obispo de Cádiz entre el 21 de febrero de 1819 y el 26 de marzo de 1824, mostrándose durante su estancia en la ciudad como firme partidario del absolutismo. Teniendo en cuenta esto, y que está en la diócesis gaditana hasta el año siguiente del resurgir de la devoción del Ángel Custodio por la promoción del rey Fernando VII, no es de extrañar que fuese el mismo obispo el causante de que se hiciera para Tarifa por Astorga. Sin embargo, consultados los libros de las visitas pastorales de Cienfuegos a Tarifa, no hemos encontrado mención alguna del obispo a la hechura de la imagen.

\section{CONCLUSIÓN}

No nos queda claro el motivo por el que se encarga la hechura del Ángel Custodio para Tarifa, y es por esto que se abren varias hipótesis: que fuera encargada por el obispo Cienfuegos o, incluso, el que pudiera estar relacionada con el fracaso de la intentona liberal del coronel Francisco Valdés que ocupó la plaza de Tarifa en agosto de 1824. Descartamos la existencia o creación de una hermandad, pues no se ha documentado esta ni consta históricamente su presencia en Tarifa. Dejamos estas hipótesis planteadas abiertas a futuras investigaciones.

Con todo, analizando ambas imágenes y comparadas con otras obras del maestro de Archidona, documentadas y atribuidas, establecemos que este conjunto escultórico puede considerarse como obra directa del escultor Juan de Astorga en los años centrales de la década de los años 20 del siglo XIX, puede que hacia 1824-1825, poco después de que Fernando VII impulsara de nuevo esta devoción que había decaído y coincidiendo con el momento en que Francisco Javier Cienfuegos estuvo al cargo de la sede episcopal gaditana.

Descubrir una nueva imagen de Juan de Astorga supone, como es lógico, un aumento de su prolífero catálogo como escultor. Que sea en Tarifa, donde se conserva un importante patrimonio imaginero cada vez más conocido, es un nuevo hito importante en la localidad pues, siendo la del Custodio una imagen del considerado mejor escultor de la primera mitad del siglo XIX de la escuela sevillana

${ }^{6}$ Amores Martínez, 2016: 363-371. 
de escultura, conlleva un mayor compromiso y la necesidad de que sea sometida a una restauración de calidad, su protección y posterior puesta en valor.

Fecha de recepción: 2 de septiembre de 2019

Fecha de aceptación: 5 de junio de 2020

\section{BIBLIOGRAFÍA}

Amores Martínez, Francisco (2016): "Una obra inédita del escultor Juan de Astorga en la iglesia parroquial de Umbrete". En: Laboratorio de Arte, 28, pp. 363-371.

Criado Atañaya, Francisco Javier (2003): "La situación de la iglesia tarifeña a principios del siglo XX. Los informes parroquiales de 1919". En: Almoraima, 5 , pp. 445-456.

Roda Peña, José (1991): "Un Niño Jesús del escultor Gabriel de Astorga". En: Laboratorio de Arte, 4, pp. 341-348.

Ruiz Alcañiz, José Ignacio (1986): El escultor Juan de Astorga. Sevilla: Diputación Provincial de Sevilla.

Terán Gil, Jesús (2002): "Documentos sobre la parroquia de San Francisco de Asís". En: Aljaranda, 46, p. 23. 


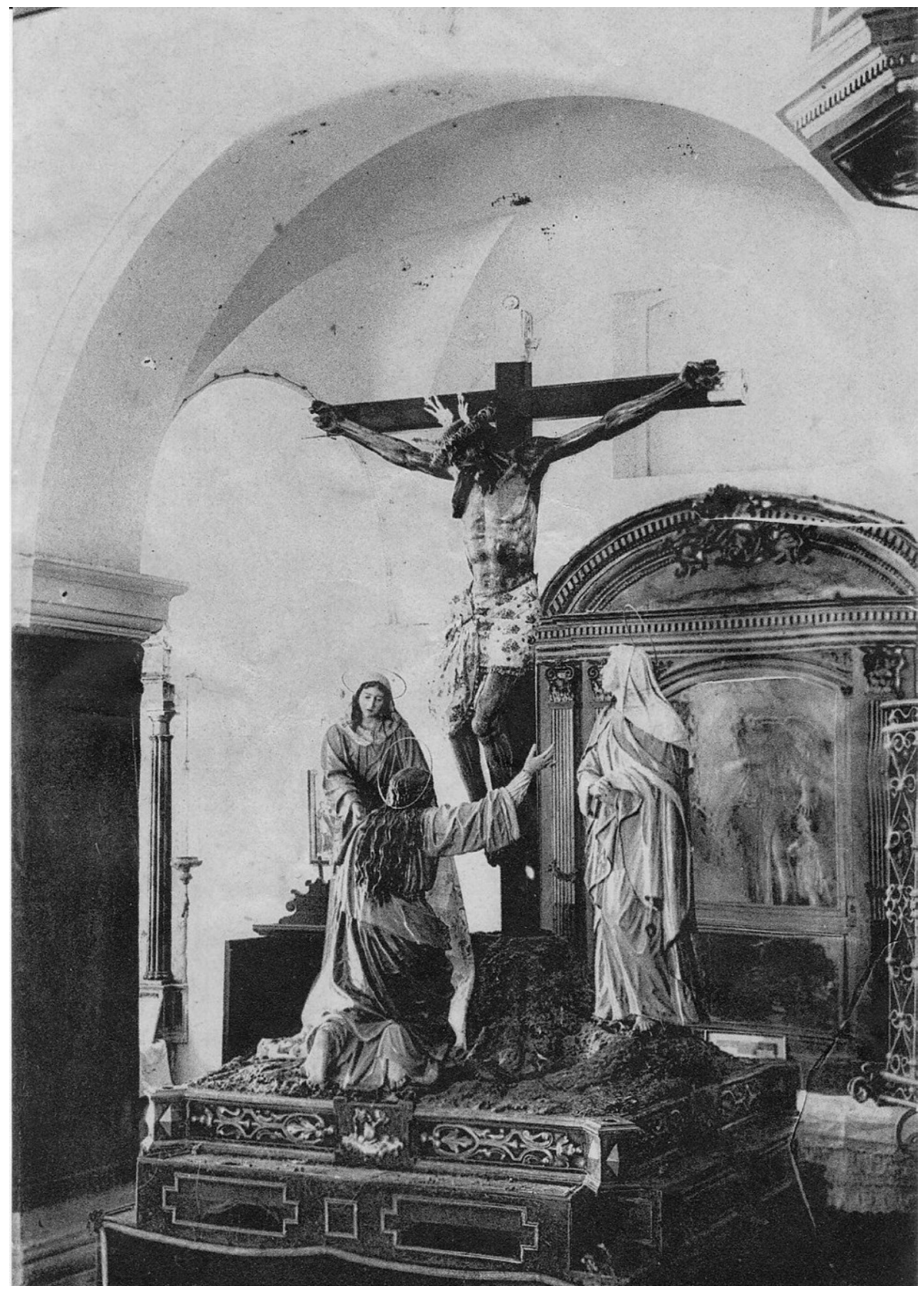

Figura 1. Juan de Astorga, Santo Ángel Custodio (en su retablo y ubicación original), iglesia parroquial de San Francisco de Asís, Tarifa. Foto: postal de los años 40 del siglo XX. 


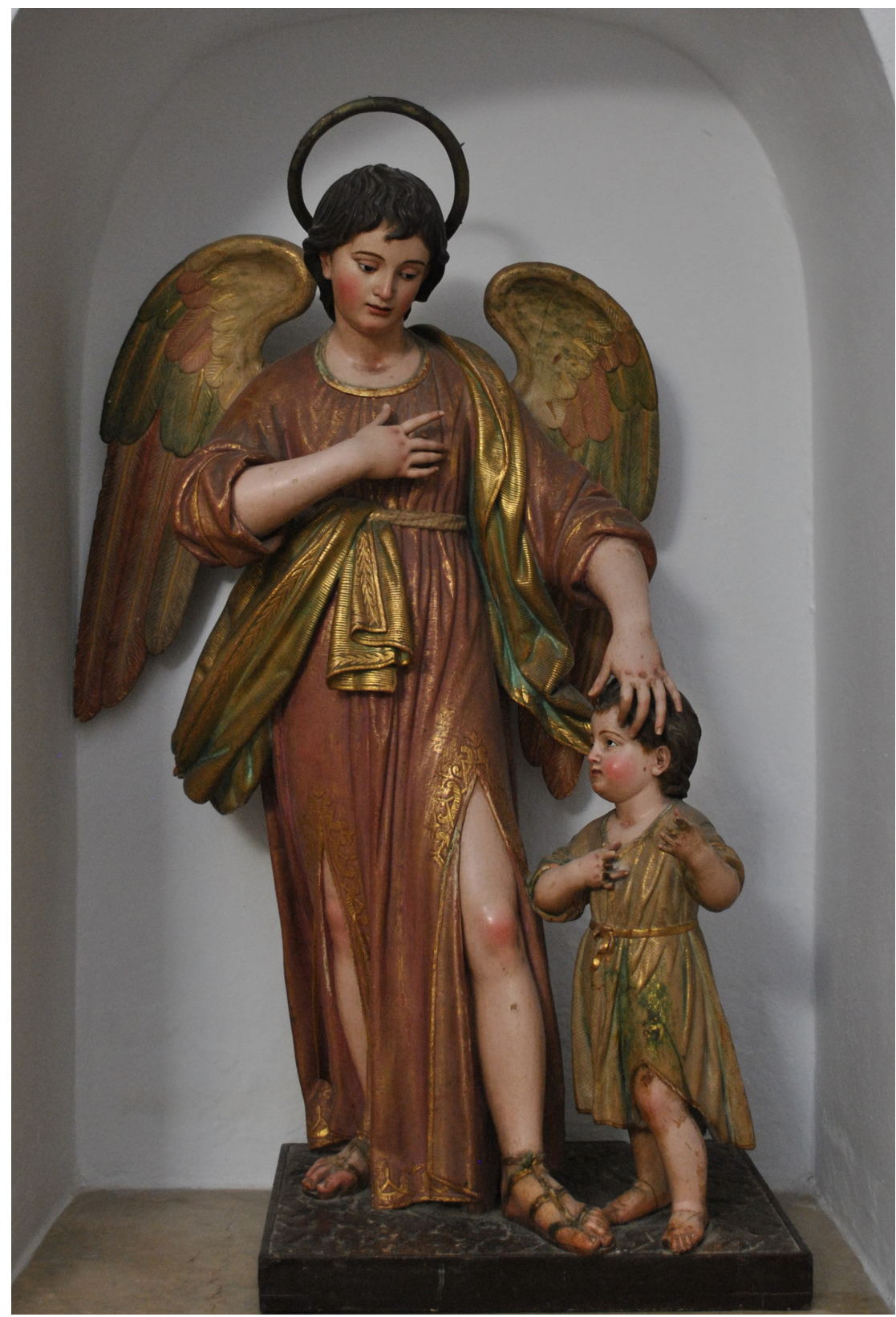

Figura 2. Juan de Astorga, Santo Ángel Custodio, 1824-1825, iglesia parroquial de San Francisco de Asís, Tarifa. Foto: Rafael Cazalla Urbano. 


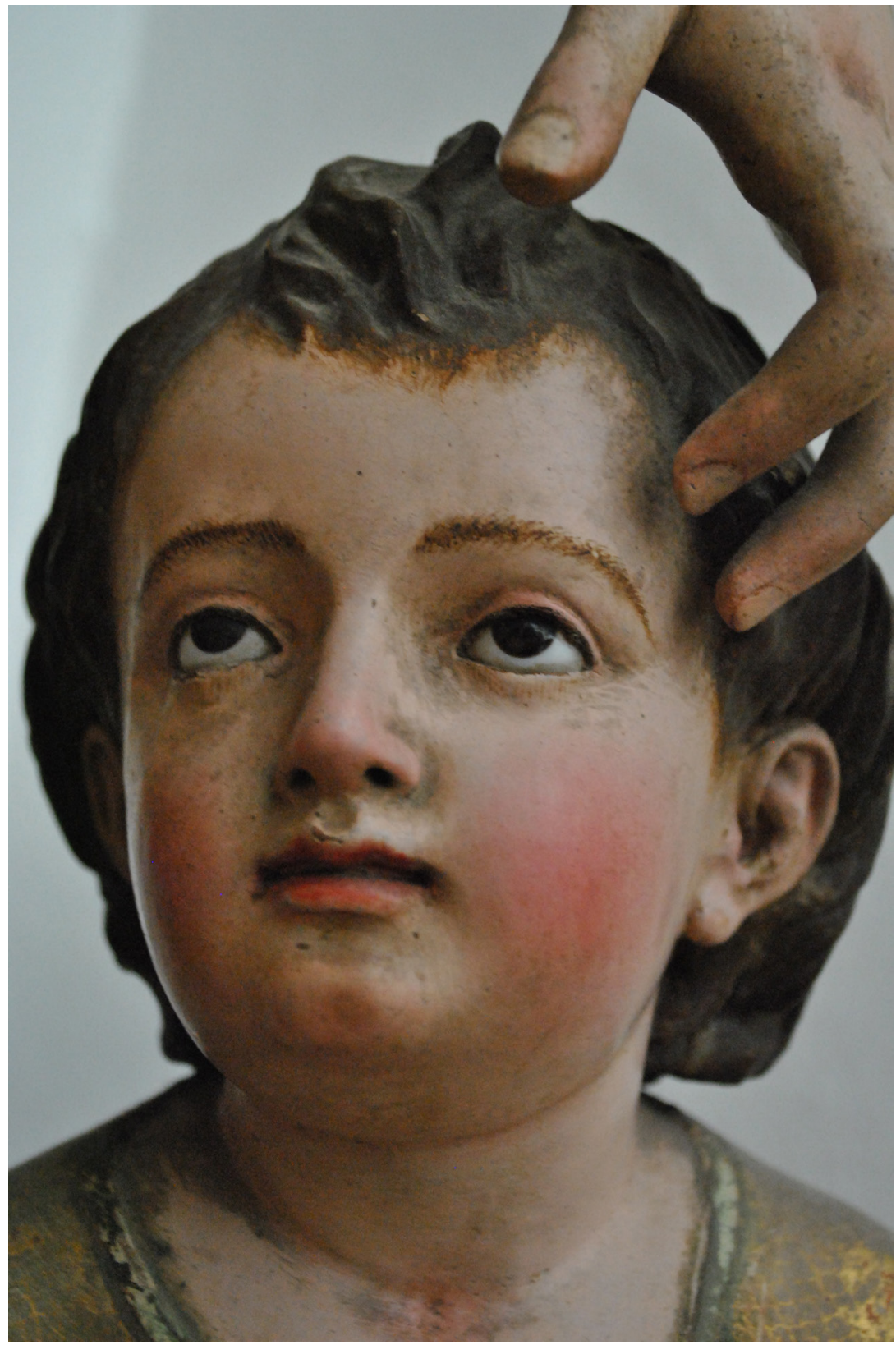

Figura 3. Juan de Astorga, Detalle de la cabeza del niño, 1824-1825, iglesia de San Francisco de Asís, Tarifa. Foto: Rafael Cazalla Urbano. 


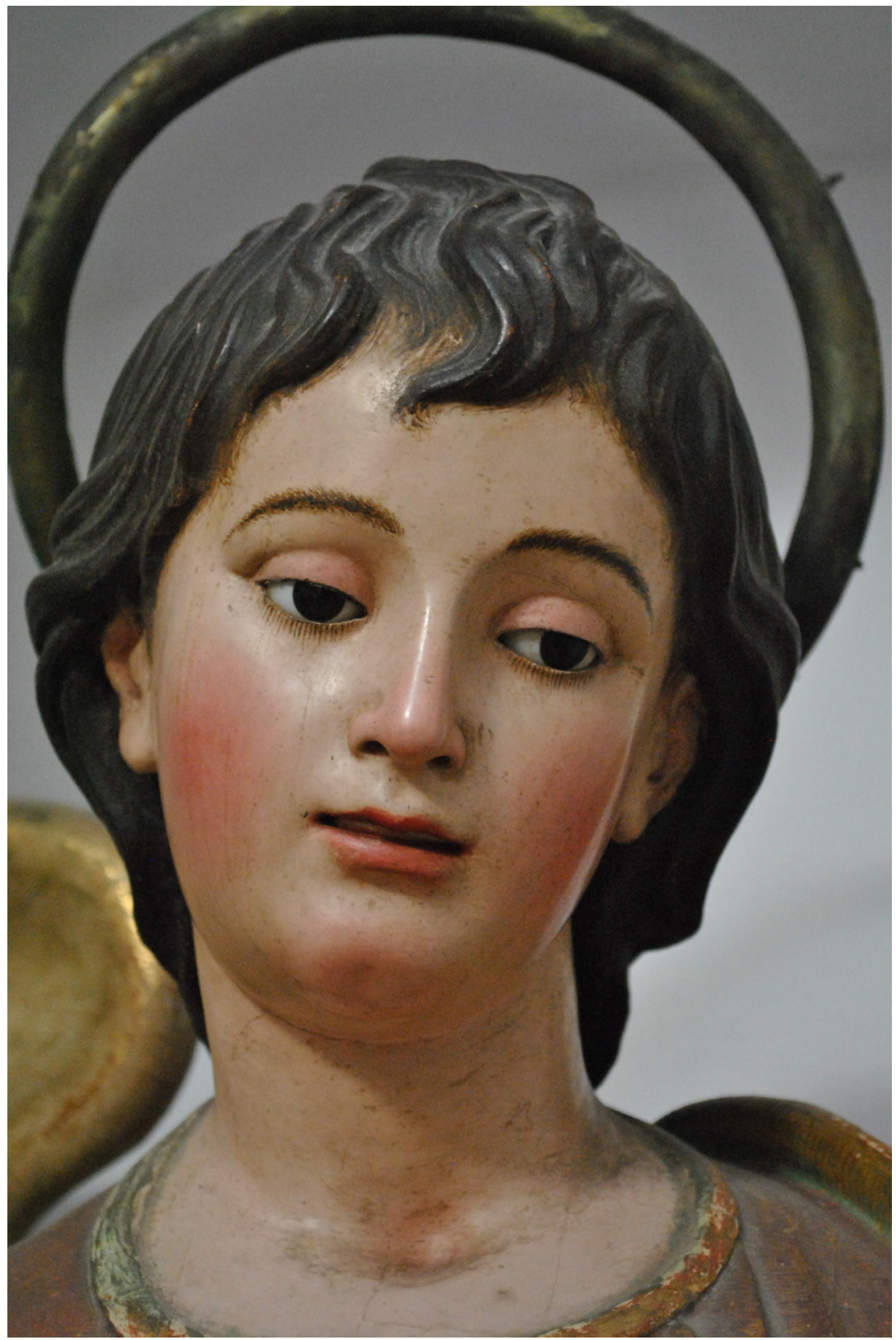

Figura 4. Juan de Astorga, Detalle de la cabeza del Santo Ángel, 1824-1825, iglesia de San Francisco de Asís, Tarifa. Foto: Rafael Cazalla Urbano. 